\title{
Kinetic and Structural Consequences Derived from Ageing Effects on Electrochemically Formed Layers
}

\author{
A. J. Arvía \\ Instituto de Investigaciones Fisicoquímicas Teóricas y Aplicadas, División Electroquímica, Sucursal 4, \\ Casilla de Correo 16, 1900 La Plata, Argentina
}

(Received 5 December 1978, revised 23 February 1979)

\begin{abstract}
The influence of different ageing processes on electrochemical reactions is analysed. Three main types of ageing processes are described: open circuit ageing, potentiostatic ageing and potentiodynamic ageing. The data derived from different electrode processes show that the films are composite systems themselves. They involve various nonequilibrated species which accordingly react to attain either a single equilibrium configuration or a configuration involving equilibria among the various surface species. Surface restructuring and cluster-type reactions are important contributions toward understanding the dynamic behaviour of electrochemical interfaces.
\end{abstract}

\section{INTRODUCTION}

Until recent years most of the experimental data on electrochemical kinetics were confined to reactions under stationary state conditions. The information on the diffusional kinetics and Tafel plot relationships is very useful particularly from the operational viewpoint, but it is rather limited in furnishing the detailed mechanisms of the electrochemical reactions. Thus, the influence of electrode surface structure on electrochemical reactions, the contribution of the solvent to electrochemical interface configuration and the participation of adsorption and electrosorption processes, including ion adsorption can only be indirectly deduced from the stationary state data. At present, however, this situation is rapidly changing with the introduction of new, powerful electrochemical relaxation methods. These can be either single or coupled to optical techniques which allow finer details to be distingusihed and new processes and intermediates involved in electrochemical reactions. Thus, through the different types of electrical perturbations, it becomes possible to confine the response of the electrochemical interface mainly to one particular contribution out of the various ones entering the electrode reaction. Despite the large amount of knowledge acquired from the application of new techniques, the number of unsolved problems is so exceedingly large that a complete understanding of the electrochemical reactions seems still far away. Therefore, the feeling exists that most of the earlier simple formalisms applied to explain the dynamic behaviour of the different types of electrode processes should be thoroughly revised through the light of the new and recent findings.

The response of the electrochemical system to a particular stimulus (perturbation) depends on the coupling between the characteristics of the perturbation and those defined as the proper system's inertia. Then, for each particular system, it is reasonable to expect a particular response for each perturbation program imposed on it. This basic concept implies two possibilities which require special attention. The first is that the kinetics of a particular physicochemical system under relaxation conditions should, in principle, differ from that observed under stationary state conditions. A coincidence of responses which may occasionally exist under special circumstances should not be taken for granted. The second question regards the fact that each type of perturbation has its own characteristic response. Thus, the change of the system's characteristics produced by a particular stimulus usually brings out only partial information about it. So, by adjusting the experimental conditions adequately it would be possible to get a maximum coupling between a particular step of the electrochemical process and the perturbation programme. Therefore, to arrive at a reasonably detailed and sound explanation of the physicochemical behaviour of the system, the correlation of data derived from the application of a wide variety of perturbation programmes seems unavoidable.

The preceding approach is exemplified through the study of the ageing processes occurring at electrochemical interfaces, in order to tackle basic problems of electrochemical reactions covering from corrosion and passivity to electrocatalysis. The idea of ageing was introduced in electrochemistry sometime ago as a possible contribution when either a new phase (multilayer) or a monolayer was formed on the electrode surface in the course of the reaction. ${ }^{16}$ The word ageing was coined to define the effect of different processes or side effects which promote a change of the electrochemical reaction response involving any kind of layer or film formation, as if the products initially formed suffered additional changes to attain more stable energetic configurations. The ageing effects, which are associated with a relatively large number of electrochemical processes, ${ }^{1-15}$ were not formerly considered except in a few cases involving oxygen containing films formed on noble metal electrodes. ${ }^{1-6}$ Consequently, the kinetic data of many electrode reactions were obtained under strictly noncomparable conditions. The ageing effects of many reactions are now recognized. Most of these effects are related to corrosion and passivation of metals in aqueous solutions. Hence, the mechanistic conclusions, which were derived by ignoring the ageing effects, are open to criticism.

The existence of either long range or short range ageing processes is very straightforwardly demonstrated in many electrochemical systems by the use of different complex multiple potential time perturbation program- 
mes, ${ }^{4-16}$ although at present the mechanisms of the ageing processes are not fully understood.

\section{AGEING PROCEDURES}

The simplest ageing process is denoted as open circuit ageing. It results, for instance, when a new species is produced on the electrode surface under an anodic linear potential sweep up to a potential value at which the electrolysis is immediatly switched off for a certain length of time. Finally, the anodically formed species is electroreduced after ageing with a linear cathodic sweep. The open circuit ageing manifests itself, under constant perturbation parameters, by a shift of the electroreduction potential towards more cathodic values, as the lapse of time from switchoff increases. Usually, a limiting electroreduction potential can be achieved. The charge taking part in the electroreduction process is equal to that participating in the electroformation process. This is so if the number of electrons per reacting species is the same for both electrode reactions and the electroformed species undergoes no chemical dissolution.

A different and more complex type of ageing is observed when the interface is perturbed in the following way. As in the former case, the anodic species is produced on the electrode surface by an anodic potentiodynamic sweep. However, once the anodic potential limit is reached, the potentiodynamic sweep is reversed towards the cathodic direction until the null current is attained. The null current potential may be located at any potential from the anodic potential limit downwards, depending on the degree of reversibility of the electrode reaction. Once the null current potential is attained, the system is held at this potential for a certain length of time and afterwards the cathodic potential sweep is continued. At the null current potential different processes are possible. As the film electroformation and electrodissolution occur at the same rate, only partial ageing effects result. Then, a film of average characteristics different from those corresponding to the open circuit aged film is produced. In this case, the participation of chemical dissolution processes is also feasible. The electroreduction of the null current potential aged film also comprises a shift of its electroreduction potential towards more negative values than those corresponding to the nonaged film. The corresponding $E / I$ contour however, should be more complicated than that of the open circuit aged film. For the null current potential ageing the cathodic charge may be either equal, lower, or higher than that recorded during the electroformation process. In general, this type of ageing procedure is referred to as potentiostatic ageing. It is especially suitable for studing multilayer formation processes involving the participation of different species with relatively close electroformation potentials.

The so-called ageing effect can also be promoted in a more elaborated way as it is the case of potentiodynamic ageing. ${ }^{17}$ In this case a film is first produced at the electrochemcial interface by means of an anodic potentiodynamic sweep at a certain rate. Immediately afterwards, the system is perturbed with a repetitive triangular potential sweep of either the same or another sweep rate during a certain preset length of time. The repetitive triangular potential perturbation is confined to potential limits which are associated just with the removal and the reforming of a fraction of the surface layer. Immediately after the repetitive triangular perturbation, a cathodic potentiodynamic excursion at the same sweep rate as the initial one serves to determine the changes induced by the repetitive triangular perturbation, after a straightforward comparison with the initial $E / I$ display. In this way it is possible to produce most of the changes induced by the types of ageing previously described, although in some cases in an amplified way. Furthermore, additional insight on the behaviour of the first layers of the metal lattice is gained from the potentiodynamic ageing data. This involves the possible surface reconstruction processes and the penetration of foreign atoms into the metallic lattice.

Data derived from the different ageing procedures involving various electrochemical systems are described further on. Attempts are made to establish significant conclusions which include: the condition for correlating the potentiodynamic behaviours of metals, the existence of non-equilibrium configurations in film-forming reactions related to the corrosion and passivity of metals, the surface reconstruction and reaccomodation of atoms on the electrode surface with the possible penetration of atoms into the metal lattice, the metastable states at a metal surface and the hydrogen dissolution assisted process.

\section{Open Circuit Ageing}

Typical examples of open circuit ageing are shown both by monolayers and multiplayers of oxygencontaining species on several metals. ${ }^{6-10}$ Figure 1 shows the single sweep triangular $E / I$ displays obtained with the $\mathrm{Pt}$ (polycrystalline)/ $\mathrm{KHSO}_{4}$ (melt) interface at $227^{\circ} \mathrm{C}^{6,7}$ The electrochemical interface consists of a polished polycrystalline platinum wire (spectroscopically pure, Johnson and Matthey) immersed in the melt prepared from a.r. chemicals (Mallinckrodt). During each anodic potential excursion up to $E_{\lambda, a}$ the electrode surface becomes covered by a monolayer of an oxygencontaining species approaching the PtO stoichiometry, as compared to the hydrogen adatom monolayer on

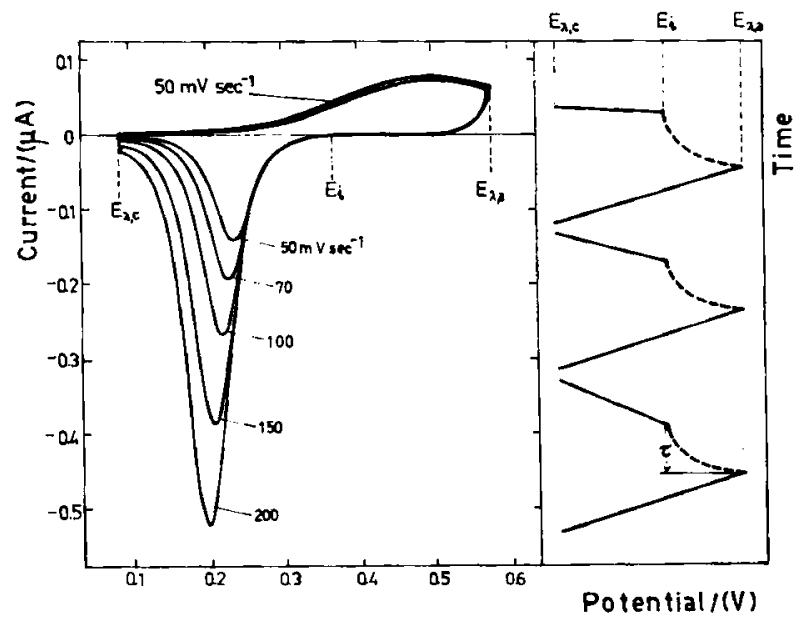

Fig. 1. Potentiodynamic $E / I$ displays covering a constant potential amplitude for the $\mathrm{Pt} / \mathrm{KHSO}_{4}$ (meit) at $227^{\circ} \mathrm{C}$ at $0.05 \mathrm{~V} \mathrm{~s}^{-1}$ anodic potential sweep and $0.05,0.07,0.10,0.15$ and $0.20 \mathrm{~V} \mathrm{~s}^{-1}$ cathodic -potential sweep, including the open circuit ageing during $\tau=1.25 \mathrm{~min} . E_{i}$ is the potential of the cathodic sweep initiation. The potential is referred to the hydrogen electrode potential in the molten electrolyte. The potential/time perturbation program including the cathodic $\left(E_{\lambda, c}\right)$ and anodic $\left(E_{\lambda, c}\right)$ switching potentials are indicated in the figure. Electrode area $0.524 \mathrm{~cm}^{2}$. 
platinum, taking the roughness factor correction into account. ${ }^{6.7}$ The same amount of $\mathrm{PtO}$ species electroformed at $v_{a}=0.05 \mathrm{~V} / \mathrm{s}$ is open circuit aged during $1.25 \mathrm{~min}$. Afterwards, the anodic product is electroreduced at different potential sweep rates $(0.05 \mathrm{~V} / \mathrm{s} \leqq$ $v_{c} \leqq 0.20 \mathrm{~V} / \mathrm{s}$ ). The electroreduction process is characterized by a cathodic current peak at ca. $0.2 \mathrm{~V}$ (vs. $\mathrm{Pt} / \mathrm{H}_{2}(1 \mathrm{~atm}) / \mathrm{KHSO}_{4}$ (melt) electrode). The open circuit ageing produces a time-independent $E / I$ profile, and the total charge remains constant, as no chemical dissolution exists. The cathodic current peak-height increases linearly with the cathodic sweep rate, and the current peak potential shifts towards more negative potentials according to a linear potential vs. $\log v_{c}$ relationship. It is likewise predicted by the linear potential sweep theory of simple electrochemical monolayer reactions. ${ }^{18}$ Then, the potentiodynamic profile of the electroreduction of the aged species can be kinetically analysed in terms of relatively simple irreversible reaction mechanisms. ${ }^{6.7}$ The formation of the monolayer of $\mathrm{PtO}$ species is accounted for by the overall reaction:

$$
\mathrm{Pt}+\mathrm{H}_{2} \mathrm{O}=\mathrm{PtO}+2 \mathrm{H}^{+}+2 \mathrm{e} \text {. }
$$

The occurrence of reaction (1) implies the following equilibrium in the melt:

$$
2 \mathrm{KHSO}_{4} \rightleftharpoons \mathrm{H}_{2} \mathrm{O}+\mathrm{K}_{2} \mathrm{~S}_{2} \mathrm{O}_{7}
$$

which participates in the thermal decomposition of the melt. At $227^{\circ} \mathrm{C}$ the potentiodynamic electroreduction of the open circuit aged species anodically formed is interpreted through a reaction scheme involving an irreversible second order rate determining step where the aged species apparently satisfies the Langmuir adsorption conditions. ${ }^{7}$ For this purpose the following formal reaction scheme is considered:

$$
\begin{aligned}
& {[\mathrm{PtO}]_{\mathrm{aged}}+\mathrm{H}^{+}+\mathrm{e}=\mathrm{Pt}(\mathrm{OH})} \\
& \mathrm{Pt}(\mathrm{OH})+\mathrm{Pt}(\mathrm{OH})=\mathrm{H}_{2} \mathrm{O}+\mathrm{PtO}+\mathrm{Pt} .
\end{aligned}
$$

The equation derived from the preceding reaction scheme for the transient current under a linear potential sweep, under the assumption that the faradaic current follows a Tafel equation with the slope $R T / 2 F$, reproduces the experimental $E / I$ profiles within $1 \%$ over nearly the whole potential range, except at the more negative potentials where the hydrogen evolution reaction begins to interfere. ${ }^{7.8}$

Usually the current peaks related to the electrochemical reduction of the aged species, probably a single type species, become thinner and very symmetric in shape. The potentiodynamic $E / I$ display, considered as the electrochemical spectrum of the system, indicates that the aged species are confined to an energy range much more restricted than the wide range usually found for the non-aged surface species. ${ }^{6.7}$ In the absence of ohmic resistance and $d l$ contributions the steepness and symmetry of the potentiodynamic $E / I$ display is in part determined by the conventional Tafel slope of the irreversible reaction: the thinner the $E / I$ profile, the smaller the Tafel slope. This has been verified both for the $\mathrm{Pt}$ (polycrystalline)/KHSO $($ (melt) interface and for the Au(polycrystalline)/1 $\mathrm{M} \mathrm{H}_{2} \mathrm{SO}_{4}$ (aq) and $\mathrm{Au}$ (polycrystalline)/1 $\mathrm{M} \mathrm{HClO}_{4}(\mathrm{aq})$ interfaces. ${ }^{6-9}$

The Tafel slopes that are required to simulate the $E / I$ displays of the electroreduction of the aged species decrease as the temperature increases. ${ }^{6-8}$ This occurs when this type of experiment is carried out over a wide temperature range with any of the above mentioned electrochemical systems. The phenomenological Tafel slopes are then even less than the $R T / 2 F$ ratio. If common conventional reaction mechanisms are valid in the whole temperature range for the cathodic reactions occurring on those electrochemical interfaces, it is reasonable that the Tafel slope increases accordingly with the temperature. Therefore, the straightforward application of conventional kinetic analysis, which probably by chance satisfies a single temperature experiment, cannot be extended to other temperatures. The kinetic data are derived for the electrodesorption of open circuit aged oxygen-containing monolayers on platinum and gold in the absence of chemical dissolution. It suggests that a term for the energy distribution of reactants in addition to the coverage terms should enter the kinetic equation representing the corresponding reaction model. The approach of the equilibrium energy distribution by the monolayer species implies a finite rate process for open circuit ageing, which interferes, not only all along the oxygen electrodesorption period under uncontrolled ageing but also during the monolayer electroformation process. When the ageing reaction rate is taken into account, the anodic $E / I$ profiles for the oxygen monolayer electroformation on platinum at the $\mathrm{Pt}$ (polycrystalline)/ $/ \mathrm{KHSO}_{4}$ (melt) interface can be precisely computed. ${ }^{19}$

At present only formal kinetic treatments in terms of reaction mechanisms have been advanced to explain the $E / I$ responses for the electrochemically sorbed and desorbed oxygen monolayer on platinum and gold under the ageing controlled conditions, but open circuit ageing clearly shows the complexity of the phenomena at the molecular level. A relatively fast mobility of the first layers of species operates, not only at the solution side of the electrochemical interface, but even at the metal side. This is a fact which is also demonstrated through the application of the ageing techniques described further on.

The open circuit potential ageing also furnishes the possible existence of either chemical or electrochemical dissolution processes occurring simultaneously with the electrochemical formation of the layer. The rate of chemical dissolution can be derived from the residual cathodic charge left after open circuit ageing at different times. The probable rate controlling process can also be determined. The layer dissolution, however, may also occur through a corrosion-type mechanism in the electrolyte solution. ${ }^{6-8}$

Finally, open circuit ageing offers the possibility of normalizing the potentiodynamic response of different electrode/electrolyte interfaces where any type of layer is formed, through a careful choice of the electrical perturbation variables.

\section{Potentiodynamic Ageing}

The perturbation programmes suitable to produce potentiodynamic ageing in the oxygen monolayer region are depicted in Fig. 2. The potential sweep rates as well as the switching potentials $\left(E_{\lambda, c}\right.$ and $\left.E_{\lambda, a}\right)$ of the wide potential range triangular perturbations and low potential range triangular perturbation $\left(E_{\lambda, c}^{\prime}\right.$ and $\left.E_{\lambda, a}^{\prime}\right)$ are conveniently adjusted. Figure 3 illustrates a sequence of three $E / I$ profiles run with the $\mathrm{Pt}$ (polycrystalline)/3.7 M $\mathrm{H}_{2} \mathrm{SO}_{4}$ interface according to the potential/time pro- 


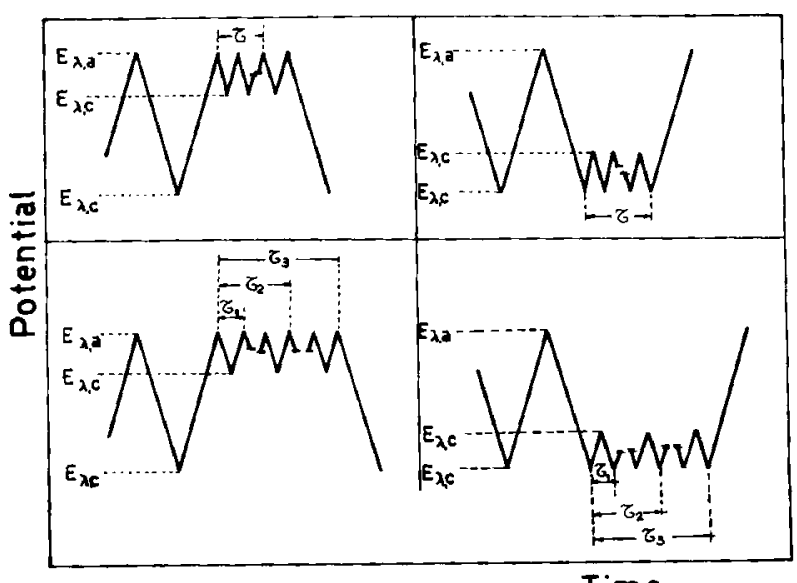

Time

Fig. 2. Different schemes of potential/time perturbation programs employed for the anodic and cathodic potentiodynamic ageings, respectively.

gramme depicted in Fig. 2. The same quality of platinum already described is employed. The electrolyte is made with a.r. $\mathrm{H}_{2} \mathrm{SO}_{4}$ and triple distilled water, which satisfied the purity criteria recommended for electrochemical kinetic studies. ${ }^{20}$ The $E / I$ profiles (Fig. 3) obtained at four different triangular perturbation times $(\tau)$ are easily compared with the conventional single triangular potential sweep $E / I$ display (full trace). The regions of the hydrogen adatoms and of the oxygen containing species are well distinguished in Fig. 3.

The potentiodynamic ageing of the oxygen elec- trosorbed monolayer within the potential range between $E_{\lambda, c}^{\prime}$ and $E_{\lambda, a}^{\prime}$ produces two main effects. At relatively short times, there is a net transformation of species, which are characterized by the electroreduction current peak at high positive potentials, into another more stable species. The electroreduction potential of the latter is not only more negative than that of the initial profile, but even more negative than the potential of the open circuit aged species obtained for the same system. As described elsewhere, ${ }^{21}$ potentiodynamic ageing attains its maximal efficiency when the intermediate perturbation entails the removal and reformation of nearly one half of the oxygen-containing monolayer. Under these circumstances the total cathodic charge remains constant during the experiments. But when the intermediate perturbation lasts longer, the cathodic charge increases causing a noticeable increase of the cathodic charge associated with the most stable oxygen-containing surface species. The potential range corresponding to the electroreduction of the latter overlaps to a considerable extent the potential range where the hydrogen electrosoption begins on platinum. This result corresponds well with the $E / I$ cathodic potentiodynamic display, run with the same electrochemical system after a prolonged anodization at high positve potentials. ${ }^{2}$

The single triangular potential sweep $E / I$ profiles run immediately after the intermediate triangular potential perturbation reveal the multiplicity of current peaks associated with the electroreduction process. It is evident that for a particular set of perturbation conditions a definite average structural $\mathrm{PtO}$ configuration is reached on the electrode surface. Therefore, the electrochemical processes can be more realistically represented by means of a more complex reaction scheme such as:

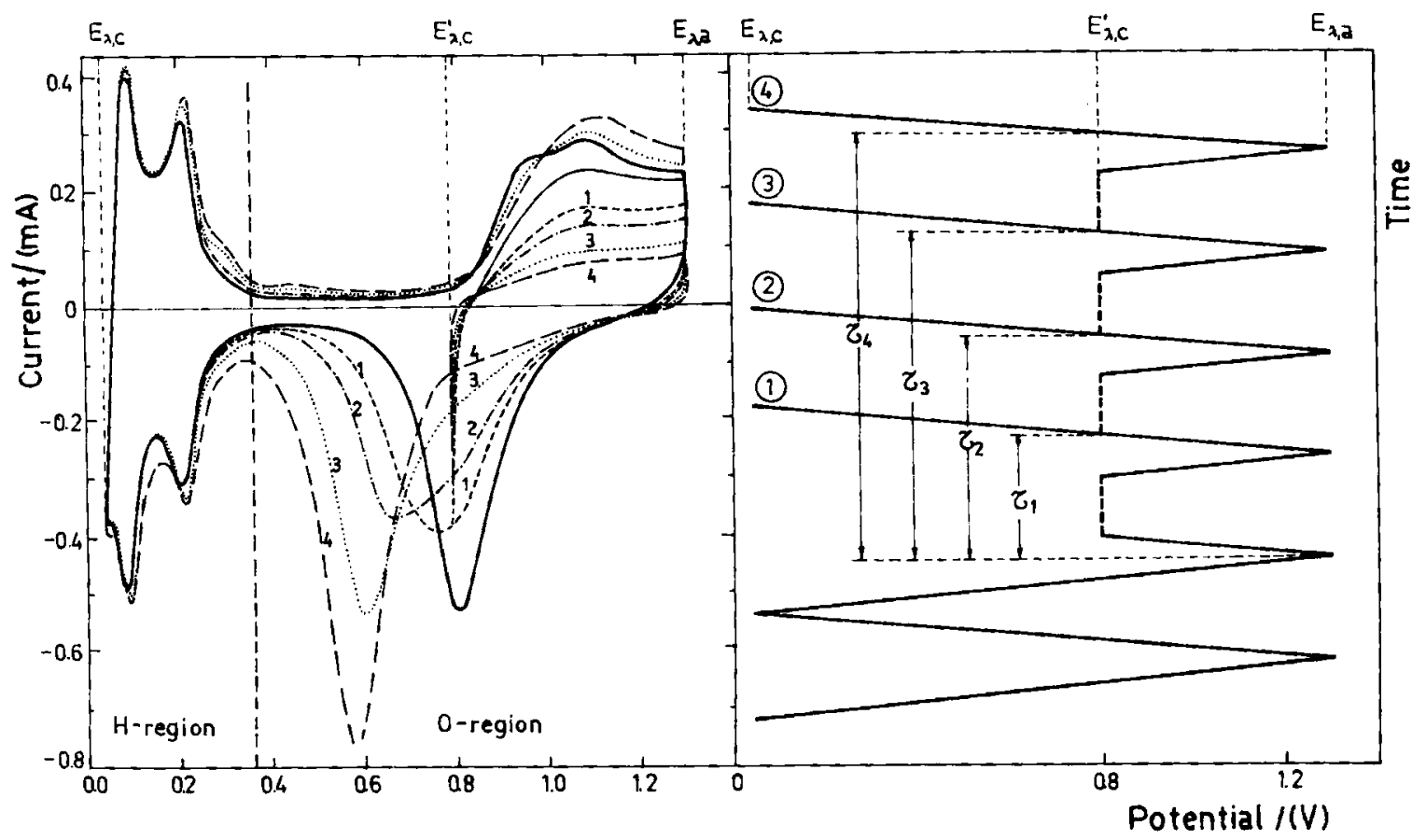

Fig. 3. Potentiodynamic $E / I$ profiles run for the $\mathrm{Pt} / 3.7 \mathrm{M} \mathrm{H}_{2} \mathrm{SO}_{4}$ interface at $55^{\circ} \mathrm{C}$. Intermediate perturbation at $0.4 \mathrm{~s}^{-1}$. Influence of the anodic switching potential. (1) $\tau_{1}=1 \mathrm{~min}$; (2) $\tau_{2}=5 \mathrm{~min}$; (3) $\tau_{3}=30 \mathrm{~min}$; (4) $\tau_{4}=90 \mathrm{~min}$. The full trace corresponds to the conventional triangular potential sweep $E / I$ display. The potential/time perturbation program is included in the figure. The potentials are referred to the RHE. 


$$
\begin{aligned}
& \mathrm{Pt}+\mathrm{H}_{2} \mathrm{O} \stackrel{(\mathrm{I})}{\rightleftharpoons} \mathrm{Pt}(\mathrm{OH})+\mathrm{H}^{+}+\mathrm{e} \\
& \text { 1L(II) }
\end{aligned}
$$

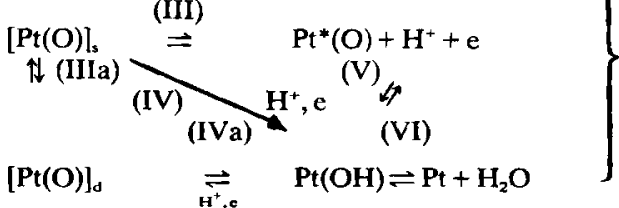

The asterisk denotes a non-equilibrium oxygencontaining species and $[\mathrm{Pt}(\mathrm{O})]_{\mathrm{s}}$ and $[\mathrm{Pt}(\mathrm{O})]_{\mathrm{d}}$ represent two aged species, the former is mainly produced during open circuit ageing, while the latter predominates under dynamic ageing conditions. Under conventional triangular potential sweep, reactions (I), (II) and (III) take place in the positive potential excursion and reactions (III), (IV), (V) and (VI) occur during the negative potential sweep.

Dynamic ageing is principally related to either reaction (IIIa) or even more likely to the sum of reactions (III) and (IIIa). The various forms of electrosorbed oxygen imply the occurrence of the complex cathodic $E / I$ potentiodynamic display involving three different electroreduction current peaks if, in principle, the potentials corresponding to reactions (IV), (IVa) and (V) are sufficiently different. The potential of the more negative electrodesorption current peak, found after dynamic ageing, coincides with the ones obtained for the reduction of multilayer oxide films on platinum. ${ }^{22}$ These results imply a possible penetration of oxygen into the metal, probably assisted by the reconstruction of the surface through dynamic ageing, that is by the redistribution of the surface metal atoms brought about by forming and breaking $\mathrm{Pt}-\mathrm{O}$ bonds.

The results of the potentiodynamic ageing experiments furnish a definite idea about the movements and surface restructuring on the electrode during potentiodynamic ageing. This has been interpreted in terms of an assisted penetration of oxygen atoms at the metal lattice sublayer. ${ }^{21}$ The frequency dependence of this phenomenon and the rate equation of potentiodynamic ageing ${ }^{21}$ clearly indicate the mobile nature of the metal surface atoms coupled to the mobile oxygen-containing entities on the surface. The coupling of reacting species mobility with the perturbation frequency results in the maximal efficiency of the dynamic process.

Potentiodynamic ageing furnishes additional kinetic data when the individual intermediate perturbation cycles are considered. The main information coming from the pertaining analysis points to either the possible accumulation or dissolution of some of the species participating in the reaction during the intermediate perturbation and the possible type of conduction mechanism at the interface. ${ }^{24}$ The former is immediately derived from the charge balance. The latter information comes directly from the slope of the individual cycles which may be either time-dependent or timeindependent. By properly adjusting the switching potentials of the intermediate perturbation, the conduction characteristics of the surface species participating in the reaction along the progressively changing potential are visualized.

The $E / I$ displays of the $\mathrm{Pt}\left(\right.$ polycrystalline)/ $1 \mathrm{M} \mathrm{H}_{2} \mathrm{SO}_{4}$ interface in the hydrogen adatoms potential range after potentiodynamic ageing (Fig. 4) reveals the change of the distribution of sites of different energies for the hydrogen adatoms as a consequence of the dynamic perturbation. ${ }^{26}$ The potentiodynamic ageing of the electrochemical interface in the hydrogen adatoms potential range (Fig. 4) furnishes another example of the change of the distribution of the sites of different energies as a consequence of the dynamic perturbation. The overall charge during the intermediate perturbation remains practically constant, but the rapid removal and refilling of the hydrogen adatoms occurs with the simultaneous reorganization of the surface in favour of the adsorption sites of higher adsorption energies. It is worthwhile to note that a similar effect can be obtained by running the $E / I$ potentiodynamic display after a long cathodization of the interface. ${ }^{26}$ This remarkable coincidence supports the idea that at least the first layers of the electrode side of the interface follow up the electrochemical changes without recovering their initial energetic configuration.

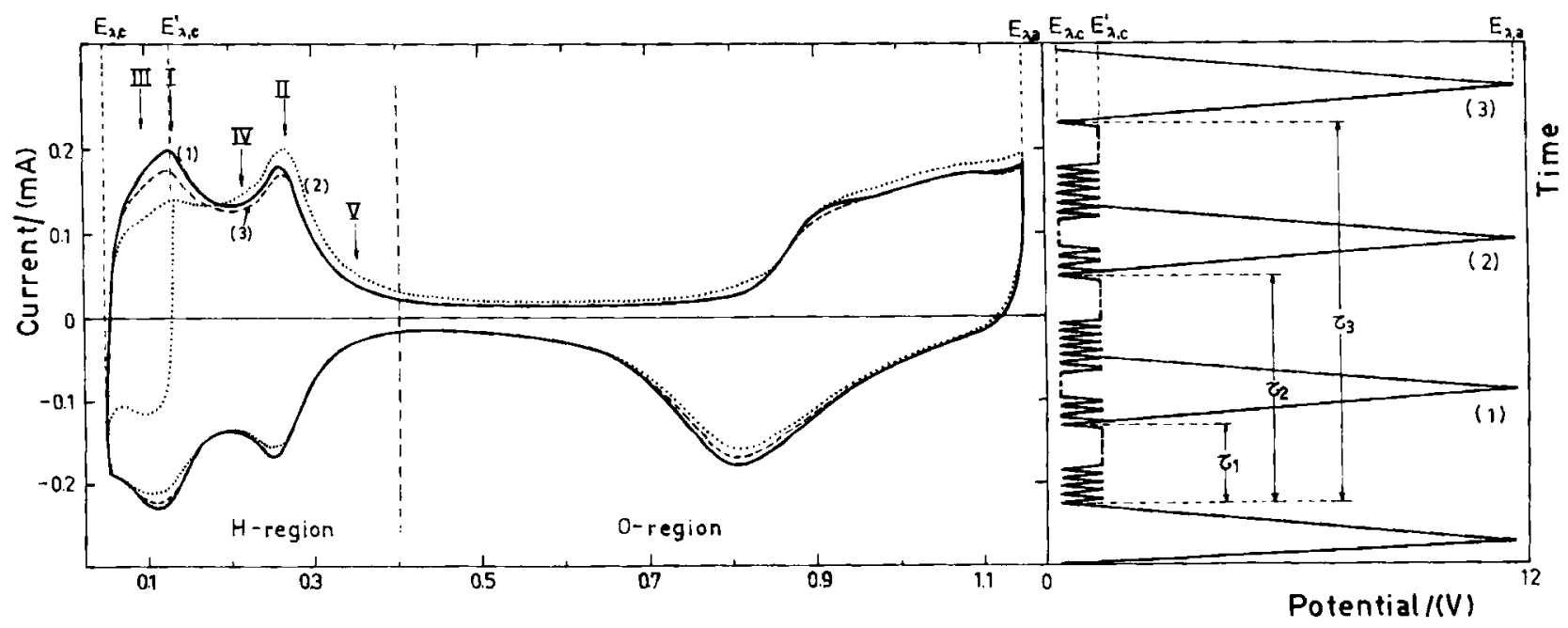

Fig. 4. Potentiodynamic $E / I$ displays for the $\mathrm{Pt} / 1 \mathrm{M} \mathrm{H}_{2} \mathrm{SO}_{4}$ interface at $25^{\circ} \mathrm{C}$, at $0.3 \mathrm{~V} \mathrm{~s}^{-1}$ according to the $E / t$ programme depicted in the figure; (-) stable profile; (..) the first trace obtained after the fast repetitive triangular potential sweeps at $3 \mathrm{~V} / \mathrm{s}^{-1}$ between $0.05 \mathrm{~V}$ and $0.13 \mathrm{~V}$ during a lapse $\tau=1 \mathrm{~min} ;(--)$ the second trace. The hydrogen electrooxidation current peaks and shoulders are numbered I, II, III and IV, respectively. The potentials are referred to the RHE. 


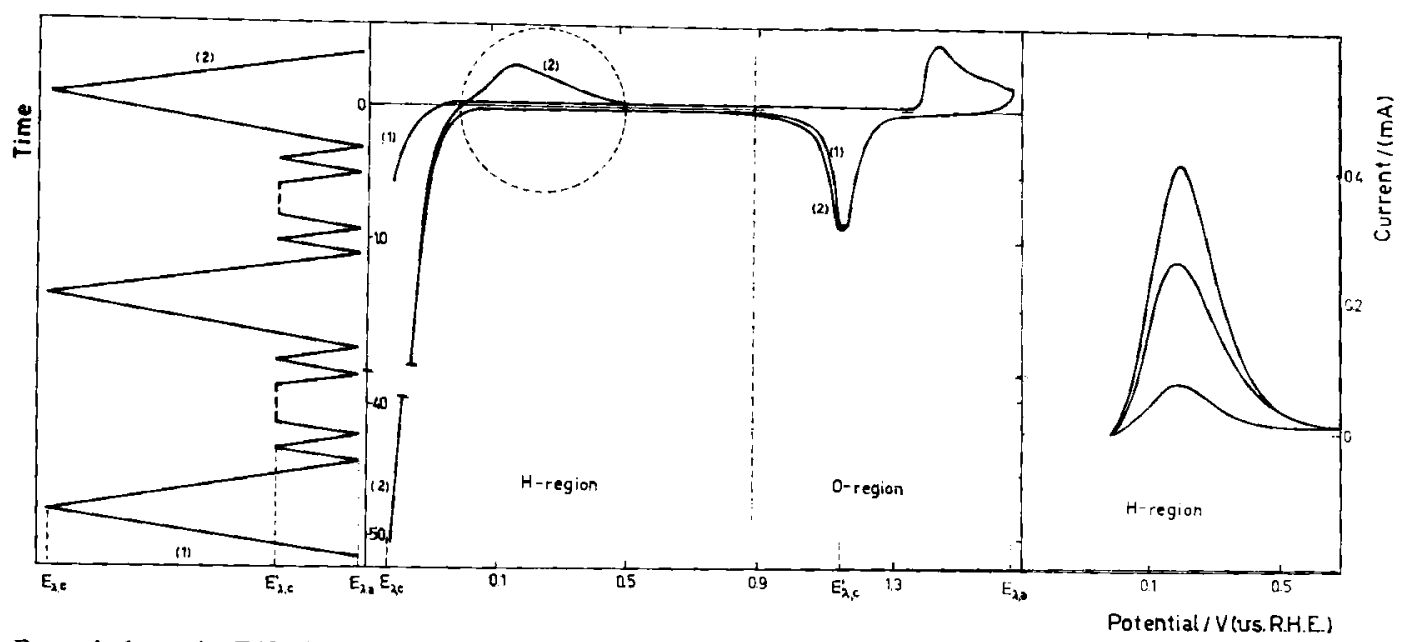

Fig. 5. Potentiodynamic $E / I$ displays obtained with the $\mathrm{Au} / 1 \mathrm{M} \mathrm{H}_{2} \mathrm{SO}_{4}$ interface at $25^{\circ} \mathrm{C}$, at $0.2 \mathrm{~V} \mathrm{~s}^{-1}$. (1) without ageing; (2) potentiodynamic ageing at $0.2 \mathrm{~V} \mathrm{~s}^{-1}$ during $30 \mathrm{~min}$. The hydrogen electrooxidation current peaks are shown with further detail at the rhs of the figure. The anodic current increase obtained after $10 \mathrm{~min}$ (a), $20 \mathrm{~min}$ (b) and $30 \mathrm{~min}$ (c) of the potentiodynamic ageing is depicted. The perturbation program is also included in the figure. The potentials are referred to the RHE.

The third interesting example of potentiodynamic ageing is that of the Au(polycrystalline)/ $1 \mathrm{M} \mathrm{H}_{2} \mathrm{SO}_{4}$ interface (Fig. 5). From thermodynamic data of the gold/hydrogen gas system it is deduced that the existence of hydrogen adatoms on gold is unfavourable. ${ }^{27}$ Despite these predictions, it has been recently found ${ }^{27}$ that, after a vigorous cathodization in the hydrogen evolution region, the immediately anodic potential sweep shows an anodic current peak just in the region where the electrooxidation of either hydrogen adatoms or dissolved hydrogen in the metal are expected. The latter response is considerably enhanced after potentiodynamic ageing of the $\mathrm{Au} / 1 \mathrm{M} \mathrm{H}_{2} \mathrm{SO}_{4}$ interface (Fig. 5). ${ }^{2 \mathrm{I}}$ In this case the ageing effect is promoted on the positive potential side, just in the potential range of the oxygen-containing monolayer electroformation and electrodissolution. Dramatic changes in the potential range of the hydrogen electrode are clearly observed, both in the cathodic reaction, whose rate increases one order of magnitude and in the hydrogen electrooxidation reaction, which is characterized by a relatively wide and asymmetric current peak. ${ }^{2 s}$ The maximum effect is again obtained when 80 percent of the oxide film is removed and reformed during potentiodynamic ageing. The successive potential cycles run, after potentiodynamic ageing, cleary show the progressive decrease of the charge pertaining to the hydrogen (dissolved and adsorbed) electrooxidation. The same $E / I$ display depicted in Fig. 5 can also be obtained in a hydrogen gas saturated solution. However, the cathodic potential limit is located slightly more positive than the potential of the net hydrogen evolution. Furthermore, under comparable perturbation conditions, the height of the electrooxidation current peak decreases under hydrogen gas stirring.

Thus, the activity of gold for the hydrogen electrode reaction can be explained in terms of the structural and energetic characteristics acquired by the first layers of gold atoms in the metal side of the electrochemical double layer. During potentiodynamic ageing the properties of those layers are definitely different from those which can be predicted from the bulk properties of the metal. Unfortunately, a quantitative description of the true surface structure, produced by potentiodynamic ageing, remains to be developed.

\section{Potentiostatic Ageing}

Potentiostatic ageing can be conceived of in at least two different ways, namely, either by keeping the interface at a fixed potential during a certain lapse of time with a net flow of current or with practically no net flow of current. The former situation usually entails a further accumulation of reaction products, a fact which makes the interpretation of the results rather more difficult. The latter case is apparently simpler but may still have additional complications as compared to those ageing procedures described before. Thus, the null current condition contains the possibility of the occurrence of an electrochemical reaction at the interface. This is the case, for instance, of a corrosion process where the base metal is electrodissolved and a second species in solution is electroreduced. Furthermore, if the metal electrodissolution is determined by the slow dissolution of the film, the continuous electrochemical formation of the latter takes place during potentiostatic ageing. In any case, the actual composition of the film corresponds to a mixture of species formed at different times. Therefore, the $E / I$ response obtained in the potentiodynamic electroreduction of the film should be intermediate between that of the non-aged film and that of the film aged under open circuit conditions. These behaviours are comparatively illustrated for the case of the $\mathrm{Pt}$ (polycrystalline)/ $/ \mathrm{KHSO}_{4}$ (melt) interface in Fig. 6. The electroreduction $E / I$ profiles become wider and more asymmetric in shape as the ageing covers the open circuit ageing, the potentiostatic ageing and the non-ageing conditions.

Potentiostating at a definite potential has been applied directly or indirectly to study different types of adsorption, either neutral species or ionic..$^{29.30}$ The interaction of these species with the electrode surface depends primarily on the location of the potential of zero charge and on the potential applied to the electrochemical interface.

The application of potentiostatic ageing is particularly useful to study the responses of the nickel hydroxide electrode in the potential range related to the overall reaction:

$$
\mathrm{Ni}(\mathrm{OH})_{2}=\mathrm{NiOOH}+\mathrm{H}^{+}+\mathrm{e} .
$$

When reaction (5) proceeds under potentiodynamic con- 


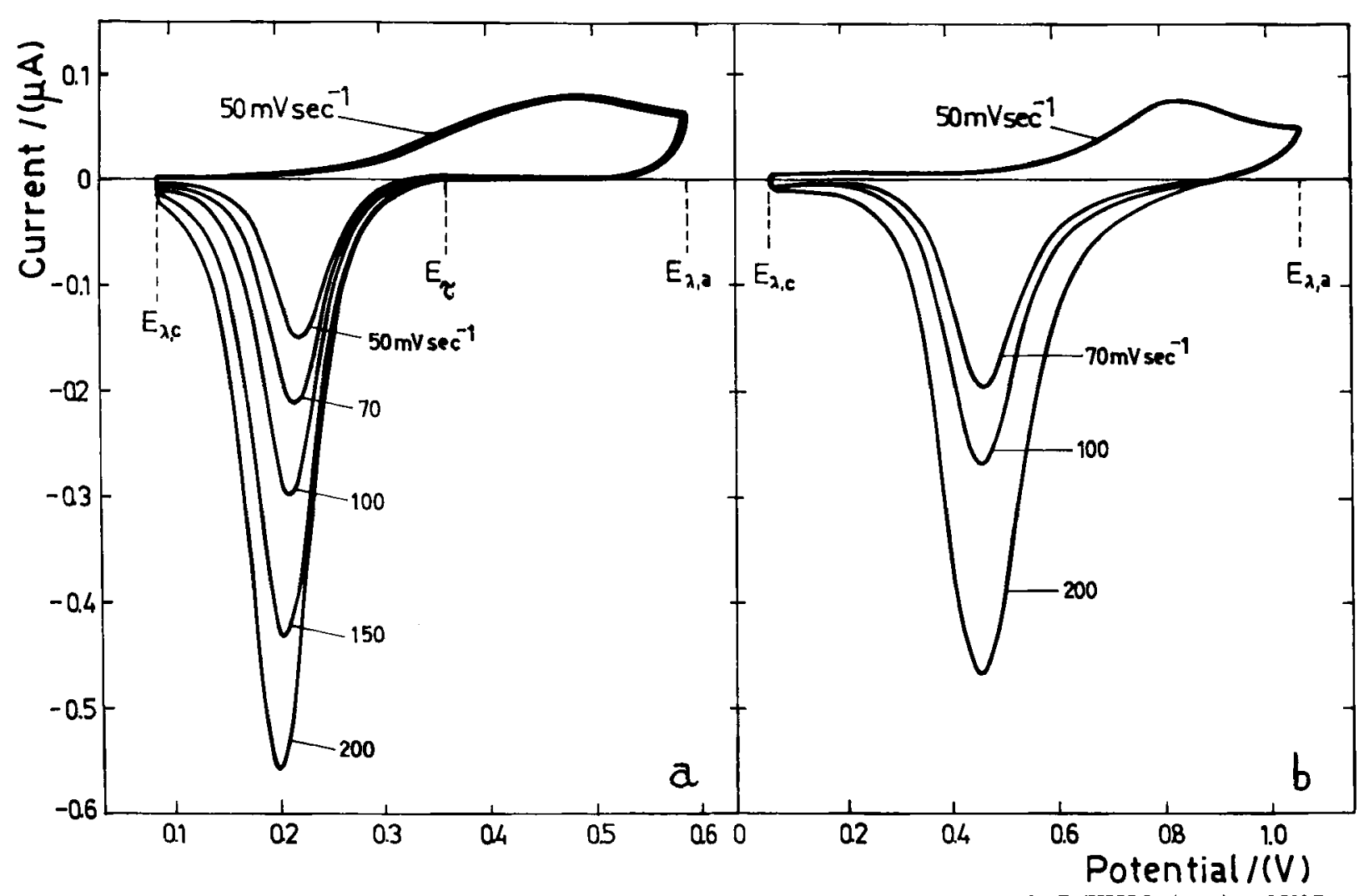

Fig. 6. Single triangular potential sweep $E / I$ displays covering a constant potential amplitude for the $\mathrm{Pt} / \mathrm{KHSO}_{4}$ (melt), at $250^{\circ} \mathrm{C}$, at a constant anodic potential sweep $\left(0.05 \mathrm{~V} \mathrm{~s}^{-1}\right)$ and different cathodic potential sweeps, as indicated in the figure. (a) Potentiostatic ageing at $E_{\tau}$ during 1 min. (b) Non-ageing conditions (conventional single triangular potential sweep $E / I$ displays).
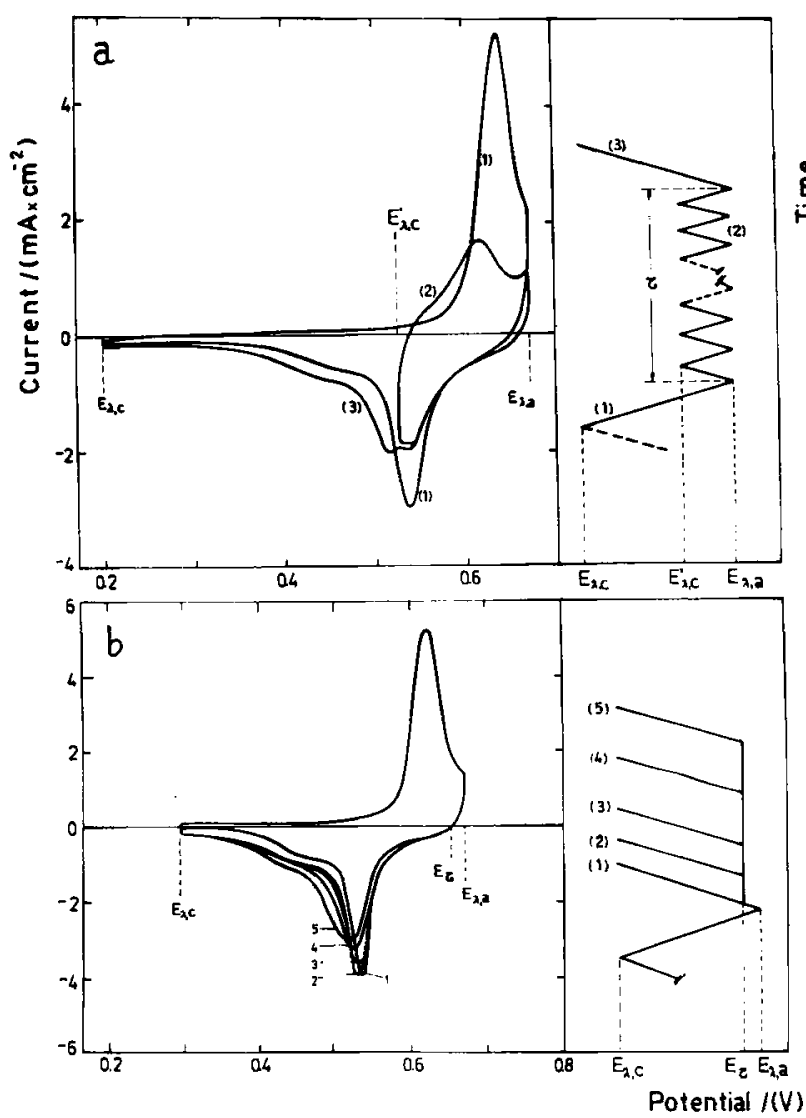

ditions without any ageing (within the potential range of water stability) an apparently simple $E / I$ display is obtained. ${ }^{31}$ But, when the electrochemical reaction proceeds from right to left after the system has been maintained at a certain $E_{\lambda, \Delta}$ and during different times E (Fig. 7), the electroreduction profile splits into two $i=$ cathodic current peaks and a shoulder. For each $E_{\lambda, a}$ the change from the single cathodic current peak to the multiple current peak display involves a constant cathodic charge. The overall electroreduction process occurs at more negative potentials as the potentiostating time at $E_{\lambda, 0}$ increases. Therefore, the potentiostatic ageing complemented by the potentiodynamic ageing reveals (Fig. 7) that the $\mathrm{NiOOH}$ electroformed species consists of at least three energetically different species. These, although probably involving a similar stoichiometry, are changing to attain an equilibrium configuration at the corresponding $E_{\lambda, a}$ value. ${ }^{11,12}$

The description of the phenomena can also be extended to the $\mathrm{Ni}(\mathrm{OH})_{2}$ species. The same type of experi-

Fig. 7. (a) $E / I$ display (3) run at $0.1 \mathrm{~V} \mathrm{~s}^{-1}$ for the $\mathrm{Ni} / 1 \mathrm{M} \mathrm{KOH}$ interface, at $25^{\circ} \mathrm{C}$, after potentiodynamic ageing at $1 \mathrm{~V} \mathrm{~s}^{-1}$ during $2 \min \left(E_{\lambda, \mathrm{c}}^{\prime}=0.53 \mathrm{~V}\right)$. Profiles indicated with number (1) correspond to the conventional stabilized triangular potential sweep $E / I$ records. The corresponding perturbation programs are included in the figure. (b) Potentiodynamic $E / I$ displays for the $\mathrm{Ni} / 0.1 \mathrm{M} \mathrm{KOH}+0.6 \mathrm{~N} \mathrm{~K}_{2} \mathrm{SO}_{4}$ interface, at $25^{\circ} \mathrm{C}$. Cathodic single triangular potential sweeps at $0.1 \mathrm{~V} \mathrm{~s}^{-1}$ recorded after attaining the profile (1) with repetitive triangular potential sweeps and then waiting $3 \mathrm{~min}$ at different $E_{\tau} \cdot E_{r}=0.78 \mathrm{~V}(2)$; $E_{\tau}=0.72 \mathrm{~V}(3) ; E_{\tau}=0.69 \mathrm{~V}(4) ; E_{\tau}=0.65 \mathrm{~V}(5) ; E_{\tau}=0.64 \mathrm{~V}$ (6). 


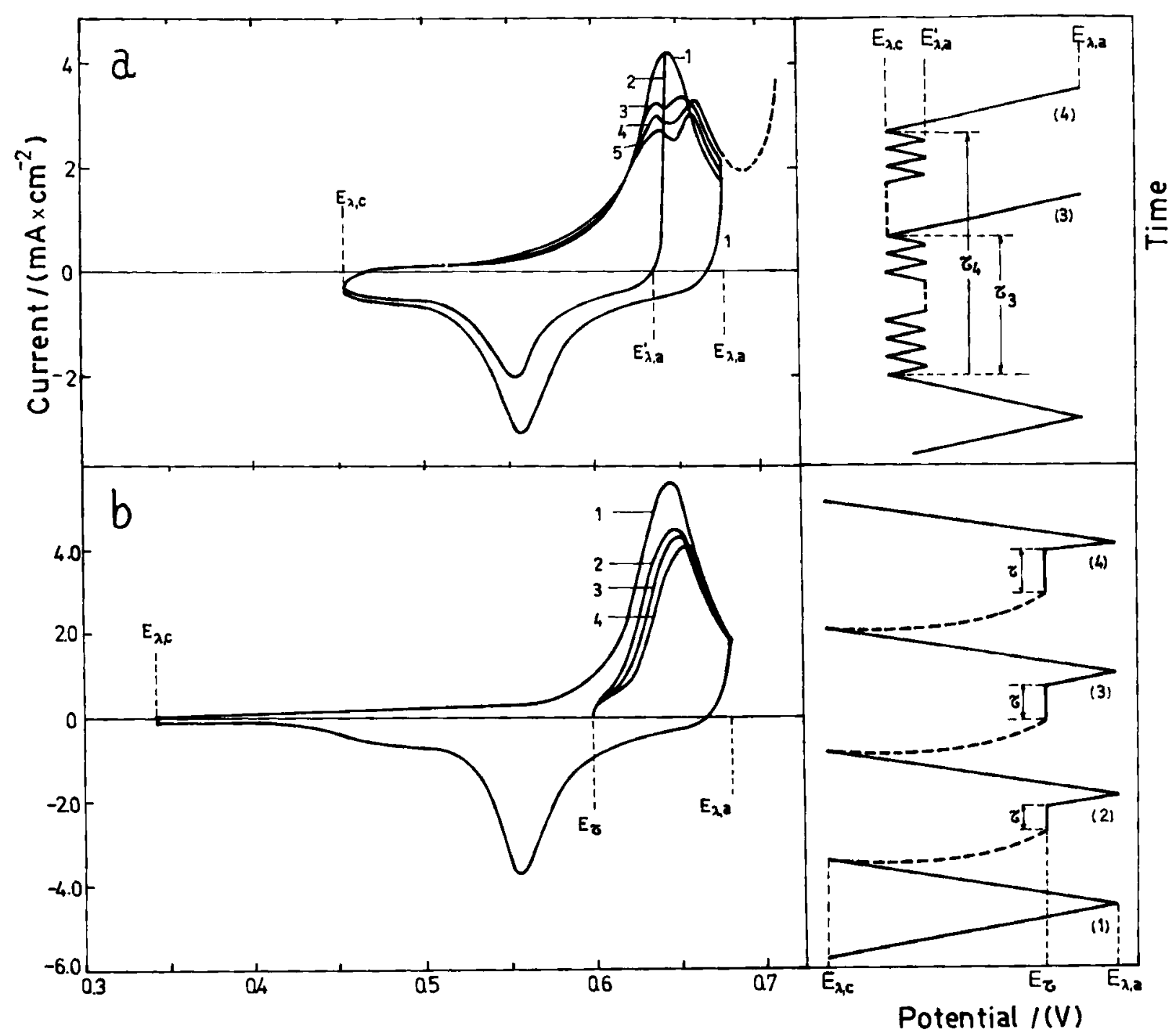

Fig. 8. Potentiodynamic $E / I$ displays for the $\mathrm{Ni} / 1 \mathrm{~N} \mathrm{KOH}$ interface at $25^{\circ} \mathrm{C}$. Profiles (1) correspond to conventional stabilized triangular potential sweep $E / I$ records. The corresponding perturbation programs are depicted in the figure. (a) Potentiodynamic $E / I$ displays run at $0.1 \mathrm{~V} \mathrm{~s}^{-1}$ obtained after potentiostatic ageing at $E_{\tau}=0.60 \mathrm{~V}$ during $0.5 \mathrm{~min}(2), 2 \mathrm{~min}(3)$ and $5 \mathrm{~min}(4)$. (b) Potentiodynamic $E / I$ displays $\left[(3),(4)\right.$ and (5)] obtained after potentiodynamic ageing $\left(E^{\prime}=0.64 \mathrm{~V}\right)$ at $0.1 \mathrm{~V} \mathrm{~s}^{-1}$ during 0.5 min, 2 $\min$ and $5 \mathrm{~min}$, respectively.

ment is carried out including a potentiostatic ageing at $E_{\lambda, c}$ during different times (Fig. 8). One immediately shows that depending on the ageing time of the $\mathrm{Ni}(\mathrm{OH})_{2}$ species at $E_{\lambda, c}$ a clear split of the anodic $E / I$ display is observed. This reveals the existence of an interconversion of at least two $\mathrm{Ni}(\mathrm{OH})_{2}$ reactant species during ageing, yielding definite electrochemical reactions at different positive potentials. In any case, the interconversion processes occurring at different $E_{\lambda, c}$ can be estimated from the charges playing part in each individual process at different potentiostating times. ${ }^{11,12}$

These results clearly demonstrate that many species are involved in the overall electrochemical reaction (5). Furthermore, they demonstrate that the reaction follows a complex pattern. From these data, together with the results derived from the triangularly modulated triangular potential sweep perturbations ${ }^{32}$ allow the following reaction pathway for reaction (5):

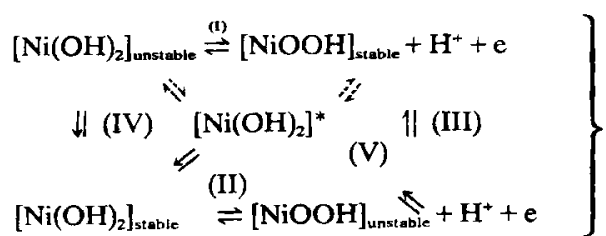

where the $\left[\mathrm{Ni}(\mathrm{OH})_{2}\right]^{*}$, represents the simplest stoichiometry for the compound bridging both main electrochemical and chemical processes participating in the square reaction model. The dashed arrows refer to possible reactions which are not detected under the present experimental conditions. This explains the apparent irreversible $E / I$ potentiodynamic displays of the nickel hydroxide electrode, the dependence of the current peaks potential location on the perturbation conditions and the fast response of the electrochemical system as far as its application to the alkaline batteries is 
concerned. A similar type of behaviour has also been established for the Fe/alkaline electrolyte interface. ${ }^{13,14}$

\section{CONCLUSIONS}

The results derived from the different ageing experiments are quite relevant to electrochemical kinetics. The existence of films, either a monolayer or multilayers, is recognized for a relatively large number of electrochemical reactions. These films are certainly composite systems involving a number of non-equilibrated species. They have been commonly considered as static, consisting of well structured stoichiometric species. Accordingly, to attain either a single equilibrium configuration or a configuration involving equilibria among the various surface species, different chemical reactions occur simultaneously during either the film electroformation or its electroreduction. Therefore, as the rate of these processes may either keep up with or lag behind the proper electrochemical reactions, it is obvious that the direct comparisons made with results obtained under different perturbation conditions, either static or dynamic is, in principle, not strictly valid for deriving sound general mechanistic conclusions. Therefore, most of the kinetic data reported in the literature obtained at a certain preset time without controlling other perturbation variables are useless for fundamental electrochemical kinetics. These types of measurements have often been done in the study of electrocatalysis as well as in corrosion and passivation of metals. Hence, it is of paramount importance for the mechanistic interpretation of the kinetic results to take into account the time scale of the function used to perturb the electrochemical interface.

The electrochemical response of the different aged layers indicates that the stoichiometric formalism of the surface species is actually more complex than that given by the stoichiometries of isolated molecules. Thus, for instance, the electrochemical reactions involving the electroformation of the oxygen containing monolayer at the $\mathrm{Pt}$ (polycrystalline)/KHSO $\mathrm{KH}_{4}$ (melt) interface is interpreted in terms of the following reaction sequence: ${ }^{19}$

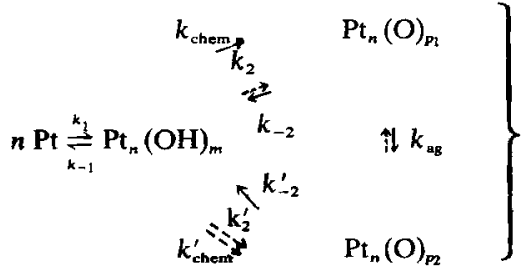

where $n$ represents the number of available platinum surface atoms; $n \geqq m, n \geqq p_{1} ; n \geqq p_{2} ; m \lessgtr p_{1}$ and $n=$ $m+p_{1}+p_{2} \cdot \mathrm{Pt}_{n}(\mathrm{O})_{p_{3}}$ and $\mathrm{Pt}_{n}(\mathrm{O})_{p_{2}}$ denote respectively the unaged and the aged oxygen species contributing to the oxygen monolayer formation. The $k$ 's denote rate constants of the different reactions. Subscript numbers indicate electrochemical steps and "chem" and "ag" mean chemical and ageing reaction respectively. The dotted arrows are unlikely processes. At the initiation of the potentiodynamic formation of the monolayer, then $n$ surface atoms are simultaneously available sites for the reaction with the water molecules. The reaction should be considered as a community process. Then, as the reaction proceeds, at any instant before the monolayer is completed, the surface layers consist of at least four different species, whose concentration ratio is timedependent both during the electroformation process and after the anodic process has been completed. When the monolayer is completed, the limiting compositions correspond to either $n=p_{1}$ or $n=p_{2}$, if the monolayer formation implies a $\mathrm{Pt} / \mathrm{O}$ atomic ratio equal to unity. Therefore, under no ageing, the average composition of the surface is time-dependent, while after the ageing reaction is completed it becomes time-independent. The electrosorption and electrodesorption processes certainly imply an alteration of the metallic bonding of the first layers of metal atoms in the lattice as compared to that of the bulk of the metal at equilibrium.

As seen from potentiodynamic ageing, the first layers of atoms in the metal lattice are relatively mobile. ${ }^{21}$ Apparently, under certain conditions, they move in phase with the dynamic perturbation. This suggests that for the present type of reactions the coupled bulk diffusion and surface diffusion processes may contribute to the penetration enhancement of the hydrogen and oxygen into the bulk of the metal. Although the ageing effects are evidenced through the layer formed on the electrode, it simultaneously reflects through the activation of the electrode surface so that the ageing effect can also be referred to the surface of the electrode, especially when the potential perturbation used removes a large percentage of the layer anodically formed.

The ageing effects indicate that surface restructuring and cluster type reactions play a very important role in the kinetic characteristics of the electrochemical reactions. Structural rearrangement and disordering of solid surfaces such as surfaces of single crystals is frequently encountered in the literature of surface science. ${ }^{33-38}$ Further advances in the knowledge of those contributions are undoubtly important to define the true energetics of the electrochemical interfaces under working conditions. Electrode surface restructuring involves at least two contributions: the first one resulting from the mobility of metal atoms because of their delocalization during the electrosorption of the oxygen containing species, and the second one related to the anisotropy of the surface energy produced by the electrosorption process.

The preceding analysis can be extended to most of the electrochemical processes involving film formation. $\mathrm{Ob}$ viously, this means that most of the simple reaction formalisms postulated to interpret the mechanisms of these reactions must be critically revised. It should be pointed out, however, that many conventional reaction formalisms are useful as operational reaction models which can be easily handled through simple equations.

Acknoledgment. INIFTA is sponsored by the Consejo Nacional de Investigaciones Cientificas y Técnicas, the Universidad Nacional de La Plata and the Comisión de Investigaciones Cientificas (Provincia de Buenos Aires). This work is partially supported by the Regional Program for the Scientific and Technological Development of the Organization of the American States. The author is indebted to Drs. M. E. Martins, N. R. de Tacconi, J. O. Zerbino, R. O. Córdova, Ing. J. Vilche and Lic. M. E. Folquer for their contributions, which are partially reported in this paper.

\section{REFERENCES}

1. S. B. Brummer, J. Electrochem. Soc., 112, 633 (1965).

2. P. Stonehart, W. A. Kozlowska and B. E. Conway, Proc. $\boldsymbol{R}$. Soc. London, A310, 541 (1969).

3. K. J. Vetter and J. W. Schultze, J. Electroanal. Chem., 34, 131 (1972); 34, 141 (1972).

4. H. Angerstein-Kozlowska, B. E. Conway and W. B. A. Sharp, J. Electroanal. Chem., 43, 9 (1973). 
5. B. E. Conway and S. Gottesfeld, J. Chem. Soc. Faraday Trans. I, 69, 1090 (1973).

6. A. J. Calandra, M. R. de Tacconi and A. J. Arvía, J. Electronanal. Chem., 49, 145 (1974).

7. N: R. de Tacconi, A. J. Calandra and A. J. Arvía, J. Electroanal. Chem., 51, 25 (1974); 57. 325 (1974).

8. C. Ferro, A. J. Calandra and A. J. Arvía, J. Electroanal. Chem., 50, 403 (1974); 55, 291 (1974); 59, 239 (1975); 65, 963 (1975).

9. J. Zerbino, N. R. de Tacconi, A. J. Calandra and A. J. Arvía, J. Electroanal. Chem., 77, 379 (1977).

10. J. Zerbino, N. R. de Tacconi and A. J. Arvía, J. Electrochem. Soc., 125, 1266 (1978).

11. R. Schrebler G., J. Vilche and A. J. Arvía, J. Electrochem. Soc., 125, 1578 (1978).

12. R. Schrebler G., J. Vilche and A. J. Arvia, J. Appl. Electrochem., 9, 183 (1979).

13. R. Schrebler G., J. Vilche and A. J. Arvía, Electrochim. Acta, 9, 321 (1979).

14. J. Zerbino, J. Vilche and A. J. Arvia, in preparation.

15. A. Castro Luna, S. L. Marchiano and A. J. Arvía, J. Electroanal. Chem., 59, 335 (1975).

16. A. J. Arvía, Anal. Real Soc. Esp. Fís. Quím., 71, 944 (1975).

17. N. R. de Tacconi, J. Zerbino, M. E. Folquer and A. J. Arvía, J. Electroanal. Chem., 85, 213 (1977).

18. S. Srinivasan and E. Gileadi, Electrochim. Acta, 11, 321 (1966).

19. J. Zerbino, R. de Tacconi, A. J. Calandra and A. J. Arvía, $J$. Electrochem. Soc., 124, 475 (1977).

20. B. E. Conway, H. Angerstein-Kozlowska, W. B. A. Sharp and E. E. Criddle, Anal. Chem., 45, 1331 (1973).

21. M. E. Folquer, J. O. Zerbino, N. R. de Tacconi and A. J. Arvía, J. Electrochem. Soc., 126, 592 (1979).
22. S. Shibata, Electrochim. Acta, 17, 395 (1972); J. Electroanal. Chem., 89, 37 (1978).

23. S. Schuldiner and T. B. Warner, J. Electrochem. Soc., 112, 212 (1965); 112, 853 (1965).

24. R. Cordova O., M. E. Martins and A. J. Arvía, J. Electrochem. Soc., in press.

25. M. E. Folquer, N. R. de Tacconi, I Vilche and A. J. Arvía, J. Electrochem. Soc., 126, 257 (1979).

26. S. Shibata, Electrochim. Acta, 22, 175 (1977).

27. F. Chao and M. Costa, C. R. Acad. Sci. Paris, 284C, 603 (1977).

28. R. Cordova O., M. E. Martins and A. J. Arvía, Electrochim. Acta, in press.

29. E. Gileadi, M. A. Fullenwider and J. O'Bockris, J. Electrochem. Soc., 113, 926 (1966).

30. V. S. Bagotskii, Yu. B. Vassiliev, J. Weber and J. N. Pirtskhalava, J. Electroanal. Chem., 27, 31 (1970).

31. J. L. Weininger and N. W. Breiter, J. Electrochem. Soc., 110, 484 (1963); 111, 707 (1964).

32. R. Schrebler, G. J. Vilche and A. J. Arvía, J. Appl. Electrochem., in press.

33. G. A. Somorjai and M. H. Farrell, Adv. Chem. Phys., 20, 215 (1971).

34. G. A. Somorjai, Principles of Surface Chemistry, PrenticeHall, Englewood Cliff, N. J., 1972.

35. R. M. Ishikawa and A. T. Hubbard, J. Electroanal. Chem., 69, 317 (1976).

36. E. Yeager, J. Physique, 38, C5-1 (1977).

37. J. C. Huang, W. E. O'Grady and E. Yeager, J. Electrochem. Soc., 124, 1732 (1977).

38. A. T. Hubbard, R. M. Ishikawa and J. Katekaru, J. Electroanal. Chem., 86, 271 (1978). 